\title{
The discovery of the genus Bryanellocoris from Laos, with description of a new species (Heteroptera: Rhyparochromidae)
}

\author{
Teruaki BAN \\ Natural History Museum and Institute, Chiba, 955-2 Aoba-cho, Chuo-ku, 260-8682 Japan; e-mail: t ban@chiba-muse.or.jp
}

Accepted:

$4^{\text {th }}$ March 2020

Published online: $12^{\text {th }}$ March 2020

\begin{abstract}
The genus Bryanellocoris J. A. Slater, 1957 (Hemiptera: Heteroptera: Lygaeoidea: Rhyparochromidae: Ozophorini) is recorded from Laos for the first time. This record is based on the discovery of a new species, Bryanellocoris wakaharai sp. nov., collected from northern Laos. Illustrations of genital structures of the new species and a key to the Oriental species of Bryanellocoris are provided.
\end{abstract}

Key words. Hemiptera, Heteroptera, Lygaeoidea, Rhyparochromidae, Ozophorini, Bryanellocoris, new species, taxonomy, key, Laos, Oriental Region

Zoobank: http://zoobank.org/urn:lsid:zoobank.org:pub:26EED260-7A4F-4C0A-8CBD-B32216629838

(C) 2020 The Authors. This work is licensed under the Creative Commons Attribution-NonCommercial-NoDerivs 3.0 Licence.

\section{Introduction}

The rhyparochromid genus Bryanellocoris J. A. Slater, 1957 belonging to the tribe Ozophorini comprises 39 species (Dellapé \& Henry 2019). The Papuan subregion is especially species-rich, and 31 species from New Guinea and Solomon Islands are known (CHEN \& AsHLOCK 1987). In contrast, only six species are known in the Oriental and eastern Palaearctic Region: B. brevicollis (Motschulsky, 1863) from Sri Lanka, B. globosus Chen \& Ashlock, 1987 from Borneo, B. hebridensis Chen \& Ashlock, 1987 from Borneo, B. orientalis Hidaka, 1962 from Korea, Japan, China and Taiwan (Zheng \& Zou 1981, Chen \& Ashlock 1987, LEE \& KWON 1991, PÉRICART 2001), B. philippinensis J. A. Slater, 1965 from Philippines, and B. pilosus Chen \& Ashlock, 1987 from Java. Through my continuing investigations, I recently discovered an undescribed species of the genus among the specimens I collected in Laos during my three visits in 2009-2010. In this paper, I describe the species under the name Bryanellocoris wakaharai sp. nov., which is also a new distributional record of the genus from Laos. I also provide illustrations of male and female genitalia for the new species and a key to Oriental species of Bryanellocoris.

\section{Materials and methods}

Dried specimens were used. For observations of genitalia, the male and female abdomens were removed from the body after the specimens were softened with hot steam. The removed parts were immersed in hot $10 \% \mathrm{KOH}$ solution for an hour, and then soaked in distilled water for further dissection. The endosoma of the phallus was everted naturally by osmotic pressure during the immersion of the phallus or was pulled out by tweezers or a needle with a shaft.

Observations of external morphology were made under a stereoscopic microscope (Olympus SZX12). Genitalia were observed and drawn by using optical microscope (Nikon Optiphot) with the aid of a drawing tube. The genitalia were then preserved in small glass tubes with glycerin and mounted on the pin with the respective specimen. Photos were taken using Color CMOS Camera system (Keyence VHX-5000). Measurements were taken by micrometer in eyepiece grid. All measurements in the text are given in millimeters.

Depositories of the specimens are abbreviated as follows:

NMPC National Museum, Prague, Czech Republic;

TUA Tokyo University of Agriculture, Atsugi, Kanagawa, Japan.

\section{Taxonomy}

Bryanellocoris J. A. Slater, 1957

Bryanella China, 1930: 135 (junior homonym of Bryanella Blair, 1928, Coleoptera). Type species by original designation: Bryanella longicornis China, 1930 (Samoa).

Bryanellocoris J. A. Slater, 1957: 37. New substitute name for Bryanella China, 1930.

Bryanellocoris: Hidaka (1962): 166-168 (fauna of Japan); Slater (1964): 1043-1044 (catalogue); SLATER (1965): 71-75 (fauna of the Philippines); Zheng \& Zou (1981): 151-152 (fauna of China); CHeN 

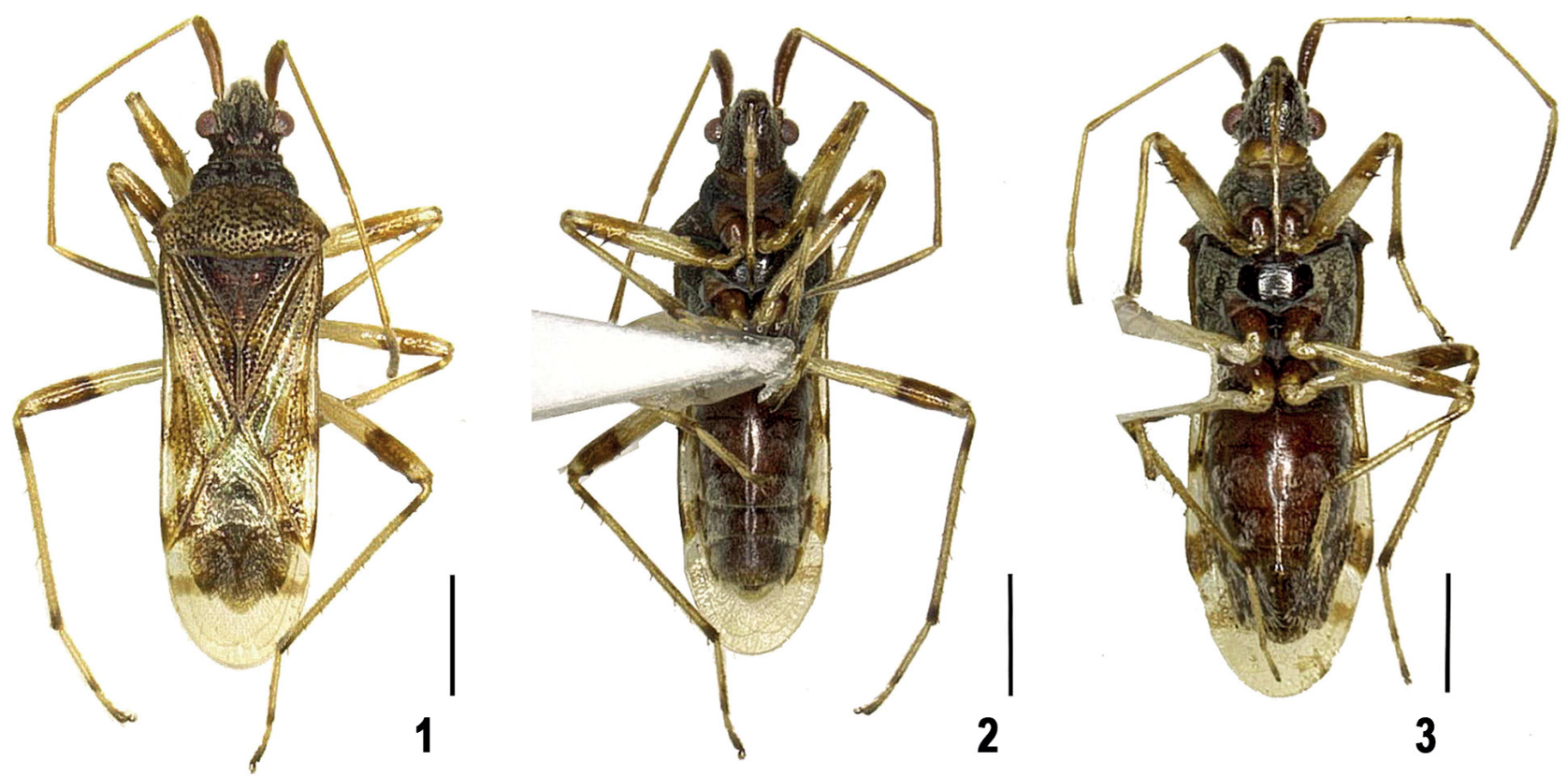

Figs 1-3. Bryanellocoris wakaharai sp. nov. 1-2 - holotype, male; 3 - paratype, female. Scale bars $=1 \mathrm{~mm}$.

\& Ashlock (1987): 393-435 (fauna of the world, in key); SLATER \& O’Donnell (1995): 133-134 (catalogue); Péricart (2001): 181 (catalogue, Palaearctic); XUE \& Bu (2004): 265-266 (larva of $B$. orientalis); AUKEMA et al. (2013): 388 (catalogue); GAO et al. (2017): 589 (abdominal trichobothria of $B$. orientalis).

\section{Bryanellocoris wakaharai sp. nov. (Figs 1-12)}

Type material. Holotype: LAOS: Oudomxay Prov.: / $11 \mathrm{~km}$ Southeast From Oudomxay: / Lak 11 Water Fall / $20^{\circ} 37^{\prime} \mathrm{N}, 102^{\circ} 00^{\prime} \mathrm{E} /$ alt. $837 \mathrm{~m}$

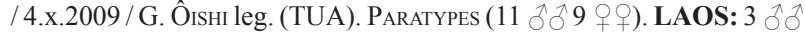
$2 \nmid \circ$, same data as holotype, G. Ôishi leg. (TUA); $8 \lesssim 7 \uparrow \circ$, same data as holotype, T. Ban leg. (NMPC, TUA).

Differential diagnosis. Recognized among congeners of Bryanellocoris by a combination of the following characters: Head dark reddish brown, antennal segment II twice as long as segment I, antennal segment IV with proximal pale band, labium reaching mesocoxae, labial segment I longer than the other labial segments, apex of carina of humeral angle acute, profemur armed with two large spines. This new species is the most similar in general appearance to B. hebridensis and B. pilosus, but can be distinguished from the latter by a combination of the following characters: Antennal segment II twice as long as segment I (in B. pilosus antennal segment II 1.5 times longer than segment I); length of setae of antennal segment I shorter than diameter of antennal segment I (in B. pilosus length of setae of antennal segment I longer than diameter of antennal segment I); basal one-fifth of antennal segment IV brownish yellow and brown in remaining part (in $B$. hebridensis antennal segment IV uniformly reddish brown); labium reaching front edge of mesocoxae (in $B$. pilosus labium reaching front edge of metacoxae); ventral surface of mesothorax matte gray (in B. hebridensis dark reddish brown and in $B$. pilosus blackish brown); corial pale spot within apical dark spot absent (in B. hebridensis corial pale spot within apical dark spot present); profemur with 2 spines (in $B$. hebridensis profemur usually with
3 or 4 spines); brown annulation of tibiae present (in $B$. hebridensis brown annulation of tibiae absent).

Description. Male. Coloration. Head (Fig. 1) dark reddish brown. Short decumbent setae on juga golden. Antennal segment I reddish brown, segments II, III and basal one-fifth of segment IV brownish yellow, apical four-fifths of segment IV brown. Labium yellowish brown; segment II pale yellow; segment IV dark brown in apical one-third. Pronotal collar brown. Pronotum (Fig. 1) dark reddish brown in anterior lobe and yellowish brown in posterior lobe, with dark spot in each humeral area. Venter of mesothorax and metathorax matte grey; peritreme dull reddish brown. Scutellum (Fig. 1) dark reddish brown, with small white spot on apex. Corium subhyaline, with brownish spot in basal one-fourth and apical one-sixth, and with pale brownish maculation in basal half to three-fourths; clavus yellowish brown, with dark spot on apex; membrane hyaline, with pale brownish marking arranged transversely in middle. Coxal cavity brown; coxae bright brown; trochanter yellow; femora yellow, with broad subapical brown annulation in apical one-third; tibiae yellow, with dark brownish annulation subbasally and on apex; tarsomere I and II yellowish brown, with dark spot on apex of tarsomere I; tarsomere III brown. Abdominal sternum reddish brown (Figs 2-3); trichobothria of abdominal segment $\mathrm{V}$ and anterior trichobothrium of segment VI pale brown. Long decumbent setae on abdominal sternum golden.

Structure. Body length 3.2 times as long as width across humeri. Head as long as wide, covered with fine punctures; juga with decumbent setae; vertex flat, covered with sparse erect setae and fine punctures. Eyes moderate in size, not stalked. Antennal segments sparsely covered with setae; segment I as long as scutellar length; proportional length of antennal segments I to IV $1.0: 2.2: 1.7: 1.7$. Labium reaching front edge of mesocoxae (Figs $2-3$ ); proportional length of rostral segments I to IV $1.7: 1.6: 1.1: 1.0$. 


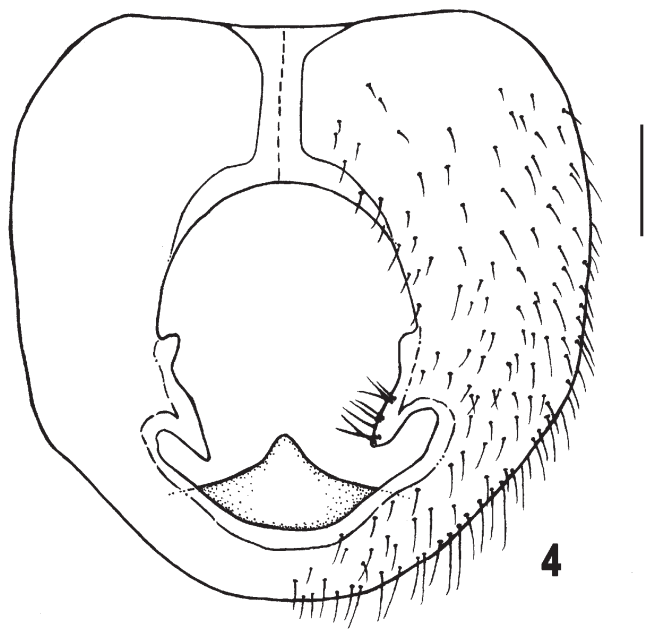

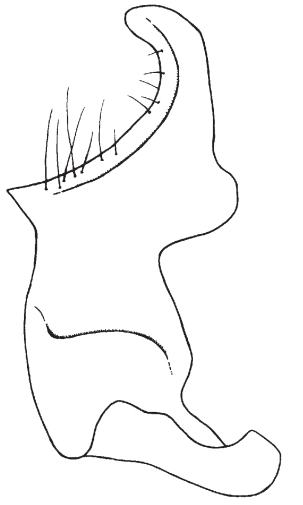

5
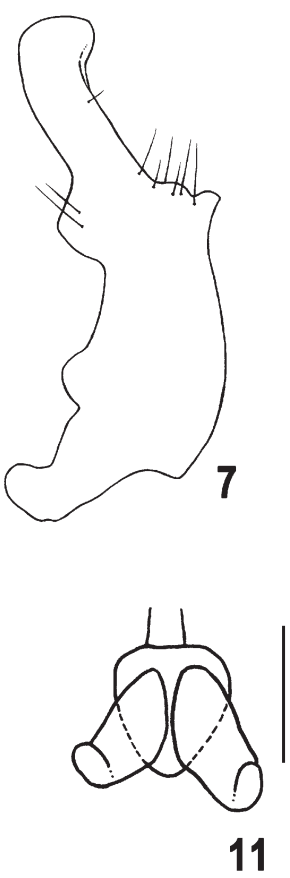

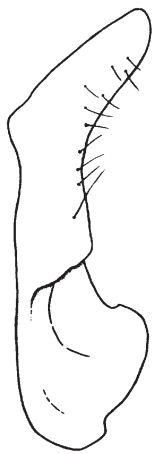

6

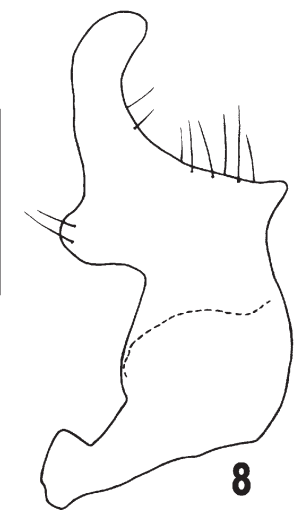

11
10

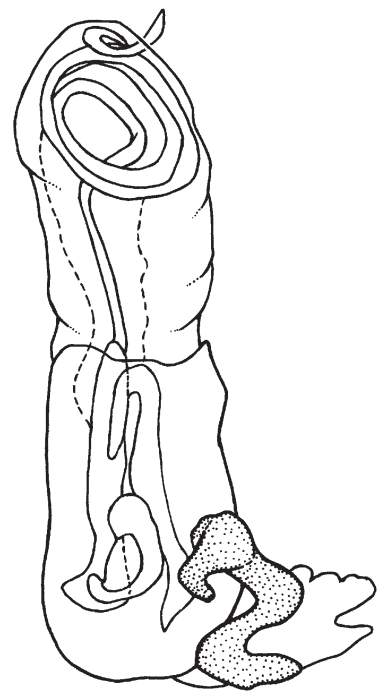

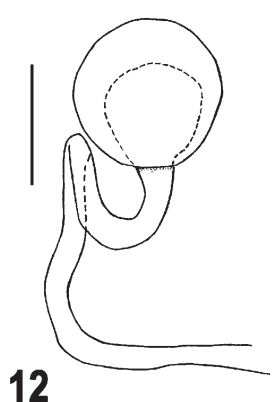

Figs 4-12. Male (4-11) and female (12) genitalia of Bryanellocoris wakaharai sp. nov. 4-pygophore, dorsal view; 5-8 - right paramere, four different aspects; 9-10 - phallus (9-dorsal view, 10 - lateral view); 11 - sperm reservoir; 12 - spermatheca. Scale bars $=0.1 \mathrm{~mm}$.

Pronotum (Fig. 1) 1.3 times as wide as long, covered with punctures and short suberect setae, without median hornlike process; with distinct transverse impression in basal twofifths, and with lateral margins weakly carinate; pronotal collar without punctures; posterior lobe 1.5 times as long as anterior lobe, distinctly tumid, apex of carina of humeral angle of pronotum acute (Fig. 1); posterior margin almost straight. Scutellum triangular, as long as wide, covered with fine punctures, with Y-shaped carina in middle. Hemelytra (Fig. 1) exceeding apex of abdomen; corium covered with sparsely erect setae and punctures; claval suture 1.2 times longer than apical margin of corium. Each femur slender; profemur ventrally armed with two large spines in about apical one-third to one-fourth; tarsus and apical one-third of each tibia densely covered with erect setae.

Abdominal sternum densely covered with decumbent setae.

Genital structures of paratypes: Pygophore (Fig. 4) globose, covered with relatively dense, erect setae; lateral margin of dorsal pygophore opening rounded, its posterior margin and cup-like sclerite not fused. Paramere (Figs 5-8) sparsely covered with erect setae; apex of outer projection rounded; apex of inner projection pointed. Phallus as in Figs 9 and 10; conjunctiva approximately of same length as phallotheca, tubular, without wrinkles or processes; sperm reservoir as in Fig. 11.

Female. General aspect as in male. Abdominal sternite VI strongly bent (Fig. 3). Ovipositor truncated at about sternite VI (Fig. 3). Spermatheca as in Fig. 12.

Measurements. Males ( $\mathrm{n}=11$, holotype in parentheses) / females ( $\mathrm{n}=9)$. Body length 4.40-4.80 (4.80) / 4.60-5.35; body height between coxae and dorsum 1.20-1.40 (1.40) / 1.30-1.45; head length $0.70-0.85$ (0.75) / 0.75-0.85; head width across eyes $0.70-0.83(0.80) / 0.75-0.86$; interocular space $0.40-0.47(0.42) / 0.44-0.50$; eye length $0.18-0.24$ $(0.21) / 0.24-0.28$; length of antennal segments I $-0.60-0.70$ (0.66) / 0.55-0.68, II - 1.20-1.43 (1.43) / 1.15-1.40, III - 0.95-1.20 (1.10) / 0.85-1.10, IV - 1.10-1.25 (1.15) / 
1.05-1.25; length of labial segments I $-0.47-0.54(0.50) /$ $0.44-0.53$, II $-0.40-0.48(0.48) / 0.36-0.49$, III $-0.28-0.35$ (0.33) / 0.30-0.35, IV - 0.26-0.34 (0.3) / 0.24-0.33; mesal pronotal length $0.95-1.13(1.13) / 1.05-1.20$; posterior pronotal width 1.28-1.45(1.45)/1.38-1.65; mesal scutellar length $0.60-0.75(0.68) / 0.65-0.75$; basal scutellar width $0.60-0.75$ (0.68) / 0.65-0.85; hemelytral length 3.05-3.40 (3.40) / 3.20-3.80; maximum width across hemelytra 1.15-1.35 (1.35) / 1.43-1.65; corium length 2.25-2.45 (2.38) / 2.30-2.75; length of claval suture $0.48-0.55$ (0.50) / 0.50-0.60; length of ovipositor 0.84-0.95.

Etymology. This species is dedicated to Mr. Hiroyuki Wakahara, a resident of Vientiane, who kindly helped me with my fieldwork.

Biological notes. Specimens were collected with several other rhyparochromid species from a mountainous forest along a mountain stream.

Distribution. Laos (Oudomxay Prov.).

\section{Key to species of Bryanellocoris from the Oriental Region}

1 Antennal segments III and IV more than twice as long as segment I; profemur with 4 or 5 spines.

B. globosus Chen \& Ashlock, 1987

- Antennal segments III and IV less than twice as long as segment I; profemur with 2 spines. ................................... 2

2 Base of antennal segment IV without pale band; labial segment III 1.8 times as long as segment I.

B. philippinensis J. A. Slater, 1965

- Base of antennal segment IV with pale band; labial segment III 0.50 to 0.75 times as long as segment I. ............ 3

3 Apex of carina of humeral angle of pronotum rounded; apical dark spot of corium inside a pale spot. ............... 4

- Apex of carina of humeral angle of pronotum acute; apical dark spot of corium without pale spot. 5

4 Head brown; anterior lobe of pronotum brown; each humeral area of pronotum without dark spot.

B. brevicollis (Motschulsky, 1863)

- Head reddish brown; anterior lobe of pronotum reddish brown; each humeral area of pronotum with dark spot.

B. orientalis Hidaka, 1962

5 Antennal segment II 1.5 times as long as segment I; length of setae of antennal segment I longer than width of antennal segment I; labium reaching front edge of metacoxae.

B. pilosus Chen \& Ashlock, 1987.

- Antennal segment II twice as long as segment I; length of setae of antennal segment I shorter than width of antennal segment I; labium reaching front edge of mesocoxae. ... 6

6 Antennal segment IV brownish yellow in basal one-fifth and brown in remaining part; ventral surface of mesothorax matte gray; corial pale spot within apical dark spot absent; profemur with 2 spines; brown annulation of tibiae present.

B. wakaharai sp. nov.

- Antennal segment IV uniformly reddish brown; ventral surface of mesothorax dark reddish brown; corial pale spot within apical dark spot present; profemur usually with 3 spines (sometimes 2 or 4 spines); brown annulation of tibiae absent

B. hebridensis Chen \& Ashlock, 1987.

\section{Acknowledgements}

I wish to express special thanks to Petr Kment (National Museum, Prague, Czech Republic), Előd Kondorosy (University of Pannonia, Keszthély, Hungary), Cuiqing Gao (Nanjing Forestry University, Nanjing, China), and Arissa Suzumura (Hokkaido University Museum, Sapporo, Japan) for critical reading and helpful comments on the manuscript. My heartfelt thanks are due to Hiroyuki Wakahara (BioNet) and Genki Ôishi (Shizuoka Pref., Japan) for helping me during my fieldwork and for providing material used in this study. I am grateful to Andrey Ozerov, Marina Krivosheina, and Nikita Vikhzef (all from Zoological Museum, Moscow University, Moscow, Russia) for taking and providing photo of the type specimen of B. brevicollis, and Wenjun Bu (Nankai University, Tianjin, China) for providing valuable literature for this study. I am much indebted to Fedor Konstantinov and Anna Namyatova (St. Petersburg State University, St. Petersburg, Russia) for contact to Zoological Museum of Moscow University. My cordial thanks to Tadashi Ishikawa (Tokyo University of Agriculture, Japan) for his continued encouragement. This study is supported by KAKENHI (21405019, head investigator: S. Okajima).

\section{References}

AUKEMA B., RABITSCH W. \& RIEGER. CH. 2013: Catalogue of the Heteroptera of the Palaearctic Region. Volume 6. Supplement. The Netherlands Entomological Society, Amsterdam, xxiii + 629 pp.

CHINA W. E. 1930: Hemiptera-Heteroptera. Insects of Samoa 2(3): 81-162.

CHEN J. X. \& ASHLOCK P. D. 1987: A revision of the genus Bryanellocoris with thirty-five new species from the Southwest Pacific (Hemiptera-Heteroptera: Lygaeidae). University of Kansas Science Bulletin 53(8): 393-435.

DELLAPÉ P. M. \& HENRY T. J. 2019: Lygaeoidea Species File. Version 5.0. Available from http://Lygaeoidea.SpeciesFile.org. (Accessed 12 November 2019).

GAO C.-G., RÉDEI D., SHI X.-Q., CAI B., LIANG K., GAO SH. \& BU W.-J. 2017: A comparative study of the abdominal trichobothria of Trichophora, with emphasis on Lygaeoidea (Hemiptera: Heteroptera) European Journal of Entomology 114: 587-602.

HIDAKA T. 1962: Studies on the Lygaeidae XXVII. Kontyu 30: 166-168.

LEE C.-E. \& KWON Y.-J. 1991: Annotated check list of Hemiptera from Korea. Part 4. Pentatomorpha 1 (excluding Pentatomidae). Nature and Life 21(1): 39-61.

PÉRICART J. 2001: Superfamily Lygaeoidea Schilling, 1829. Family Lygaeidae Schilling, 1829. - Seed-bugs. Pp. 35-220. In: AUKEMAB \& RIEGER CH. (ed.): Catalogue of the Heteroptera of the Palaearctic Region. Volume 4. The Netherlands Entomological Society, Amsterdam, $\mathrm{xiv}+346 \mathrm{pp}$.

SLATER J. A. 1957: Nomenclatorial considerations in the family Lygaeidae (Hemiptera: Heteroptera). Bulletin of the Brooklyn Entomological Society 52: 35-38.

SLATER J. A. 1964: A catalogue of the Lygaeidae of the World. I, II. Waverly Press, Baltimore, Maryland, 1668 pp.

SLATER J. A. 1965: A new species of Bryanellocoris from the Philippines (Hemiptera: Lygaeidae). Philippine Journal of Science 94(1): 71-75.

SLATER J. A. \& O'DONNELL J. E. 1995: A catalogue of the Lygaeidae of the World (1960-1994). New York Entomological Society, New York, $410 \mathrm{pp}$

XUE H.-J. \& BU W.-J. 2004: Descriptions of the immature stages of three species of the tribe Ozophorini (Heteroptera: Lygaeidae: Rhyparochrominae) from China. Entomotaxonomia 26(4): 264-271.

ZHENG L.-Y. \& ZOU H.-G. 1981: Lygaeidae. Pp. 1-215, 589-612. In: HSIAO T.-Y., REN S.-Z., ZHENG L.-Y., JING X.-L., ZOU H.-G. \& LIU S.-L.: A handbook for the determination of the Chinese Hemiptera-Heteroptera, Volume 2. Science Press, Beijing, 612 pp. 